\title{
Leishmania amazonensis: Biological and biochemical characterization of ecto-nucleoside triphosphate diphosphohydrolase activities
}

\author{
Carla M. Pinheiro a, Erica S. Martins-Duarte a, Rodrigo B. Ferraro a, \\ André Luíz Fonseca de Souza ${ }^{\mathrm{a}}$, Marta T. Gomes ${ }^{\mathrm{b}}$, Angela H.C.S. Lopes ${ }^{\mathrm{b}}$, \\ Marcos A. Vannier-Santos ${ }^{c}$, André L.S. Santos ${ }^{b}$, José R. Meyer-Fernandes ${ }^{a}$,* \\ a Instituto de Bioquímica Médica (IBqM), Universidade Federal do Rio de Janeiro (UFRJ), Centro de Ciências da Saúde (CCS), Bloco H, \\ Cidade Universitária, Ilha do Fundão, 21541-590, Rio de Janeiro, Brazil \\ ${ }^{\mathrm{b}}$ Instituto de Microbiologia Prof. Paulo de Góes (IMPPG), UFRJ, CCS, Bloco I-subsolo, Rio de Janeiro, Brazil \\ ${ }^{\mathrm{c}}$ Centro de Pesquisas Gonçalo Muniz, Fundação Oswaldo Cruz (FIOCRUZ), Salvador, Bahia, Brazil
}

Received 14 October 2005; received in revised form 2 February 2006; accepted 6 February 2006

Available online 17 April 2006

\begin{abstract}
The presence of Leishmania amazonensis ecto-nucleoside triphosphate triphosphohydrolase activities was demonstrated using antibodies against different NTPDase members by Western blotting, flow cytometry, and immunoelectron microscopy analysis. Living promastigote cells sequentially hydrolyzed the ATP molecule generating ADP, AMP, and adenosine, indicating that this surface enzyme may play a role in the salvage of purines from the extracellular medium. The L. amazonensis ecto-NTPDase activities were insensitive to Triton X-100, but they were enhanced by divalent cations, such as $\mathrm{Mg}^{2+}$. In addition, the ecto-NTPDase activities decreased with time for $96 \mathrm{~h}$ when promastigotes were grown in vitro. On the other hand, these activities increased considerably when measured in living amastigote forms. Furthermore, the treatment with adenosine, a mediator of several relevant biological phenomena, induced a decrease in the reactivity with anti-CD39 antibody, raised against mammalian E-NTPDase, probably because of down regulation in the L. amazonensis ecto-NTPDase expression. Also, adenosine and anti-NTPDase antibodies induced a significant diminishing in the interaction between promastigotes of L. amazonensis and mouse peritoneal macrophages.
\end{abstract}

(C) 2006 Elsevier Inc. All rights reserved.

Index Descriptors and Abbreviations: Leishmania amazonensis; Ecto-ATPase; Adenosine; E-NTPDase

\section{Introduction}

Parasites of the genus Leishmania present two forms in their life cycle: the spindle-shaped, flagellated promastigotes, which multiply in the midgut of the sandfly vector and oval, non-motile amastigotes, obligate intracellular forms that live inside the vertebrate host's tegument and visceral tissue mononuclear phagocyte system cells. This cell differentiation involves numerous changes and is crucial for Leishmania pathogenicity (Herwaldt, 1999). Infection by Leishmania parasites can cause, depending on the

\footnotetext{
* Corresponding author. Fax: +55 2122708647.

E-mail address: meyer@bioqmed.ufrj.br (J.R. Meyer-Fernandes).
}

parasite species, a variety of disease outcomes in humans, ranging from single self-healing cutaneous lesions to visceral dissemination of the parasite, which may lead to death if not properly treated. Furthermore, New World Leishmania species may cause severe cutaneous forms, such as diffuse or mucocutaneous leishmaniasis, widening the range of possible outcomes. For instance, Leishmania amazonensis is the causative agent of diffuse cutaneous leishmaniasis, a disease that is characterized by a decreased immune response in infected patients (Convit et al., 1972), and also often causes disseminated cutaneous leishmaniasis (Barral et al., 1991).

A number of Leishmania molecules have been implicated in parasite virulence, including the $63 \mathrm{kDa}$ surface zinc- 
metallopeptidase (Yao et al., 2003) and lipophosphoglycan (Descoteaux and Turco, 1999), as well as intracellular cysteine peptidases (Mottram et al., 2004). Recently, our group characterized an ecto-ATPase activity in promastigotes of L. amazonensis, suggesting its possible involvement in the adenosine acquisition and virulence, since parasites cultured in vitro for several years showed a reduced ATPase activity, as well as failed to induce lesions in the susceptible mammalian host (Berredo-Pinho et al., 2001). Ecto-ATPases have been described in several protozoa (Meyer-Fernandes, 2002), such as Toxoplasma gondii (Asai et al., 1995; Nakaar et al., 1998), Entamoeba histolytica (Barros et al., 2000), Tritrichomonas foetus (Jesus et al., 2002), Acanthamoeba (Sissons et al., 2004), Herpetomonas muscarum muscarum (Alves-Ferreira et al., 2003), Crithidia deanei (Dos Passos Lemos et al., 2002), Trypanosoma cruzi (Bisaggio et al., 2003; Meyer-Fernandes et al., 2004), and Leishmania tropica (Meyer-Fernandes et al., 1997).

During the last decades, considerable progress has been achieved in the study of ecto-nucleotidases including ectoATPases. This progress is related to the finding that, in contrast to the established view, nucleosides can be found in significant concentrations outside the cells, playing their effects on other cells in the vicinity of the secretion site and modulating biological processes by binding to specific cell surface receptors (Dombrowski et al., 1998). Cell membrane ecto-ATPase or NTPDase is millimolar divalent cation-dependent, presenting low specificity activities capable to hydrolyze all nucleoside triphosphates (Plesner, 1995; Zimmermann, 2001). This family has been grouped into several subfamilies depending on the extent of their sequence homology. They also differ in their abilities to hydrolyze nucleoside diphosphates, modes of anchoring to membrane, and tissue distributions (Zimmermann, 2001). E-NTPDases located at the cell surfaces (NTPDase 1-3) are involved in the regulation of purinergic signaling. EctoATPases (NTPDase2) from different species, when expressed, all share the property of displaying little activity toward nucleoside diphosphatase (Knowles and Chiang, 2003). In the present work, we demonstrate the biological and biochemical characterization of ecto-nucleoside triphosphate diphosphohydrolase activities in L. amazonensis, using Western blotting, flow cytometry, and immunoelectron microscopy analysis.

\section{Materials and methods}

\subsection{Reagents}

Media constituents, reagents used in electrophoresis, buffer components, nitrocellulose membrane, and reagents for chemiluminescence detection were purchased from Amersham Life Science (Little Chalfont, England). Adenosine triphosphate (ATP), adenosine diphosphate (ADP), adenosine monophosphate (AMP), adenosine, sodium azide, bovine serum albumin (BSA), ethylenediaminetetraacetic acid (EDTA), Hepes (4- (2-hydroxyethyl)-1-piperazineethanesulfonic acid), sodium fluoride, sodium vanadate, ammonium molybdate, mannitol, dithiothreitol (DTT), phenylmethylsulfonyl fluoride (PMSF), trans-epoxysuccinyl L-leucylamido-(4guanidino) butane (E-64), pepstatin A, and all commercial antibodies were obtained from Sigma Chemical Co. (St. Louis, MO, USA). Tetrabutylammonium bromide (TBAB) and all other solvents were purchased from Merck (Damstadt, Germany).

\subsection{Microorganism and growth conditions}

Leishmania amazonensis (MHOM/BR/75 Josefa strain), originally isolated from a human case of cutaneous leishmaniasis, was kindly provided by Dr. Cesar A. C. Cuba (Universidade de Brasília, Distrito Federal, Brazil) and used throughout this study. Promastigote forms were cultured in Warren's medium supplemented with $10 \%$ heatinactivated fetal bovine serum (FBS) at $22^{\circ} \mathrm{C}$ for $24-96 \mathrm{~h}$. In vitro promastigote-amastigote differentiation was carried out as previously described (Alves et al., 2005). Alternatively, promastigotes were grown in Warren's medium supplemented with $10 \% \mathrm{FBS}$ in the absence or presence of 0.5 and $5 \mathrm{mM}$ adenosine at $22^{\circ} \mathrm{C}$ for $72 \mathrm{~h}$ (Berredo-Pinho et al., 2001). Cellular growth was estimated by counting the parasites in a Neubauer chamber. Cellular viability was assessed, before and after incubations, by motility (only for promastigotes), as well as by light microscopy observation using Trypan blue cell dye exclusion for both promastigote and amastigote forms.

\subsection{Reverse-phase HPLC analysis}

The HPLC system consisted of LC-10At pump, FCV10AL solvent mixer, DGU-14A degasser, SPD-M10A diodearray detector, and a CLASS-LC10A (version 1.41) computing integrator; Shimadzu (Kyoto, Japan). The flow rate was maintained at $2 \mathrm{ml} / \mathrm{min}$. The separation of the nucleotides and nucleosides was achieved by ion-pair reverse-phase chromatography on an analytical Supelcosil LC-18 $(46 \times 250 \mathrm{~mm}, 5 \mu \mathrm{m}$ particle diameter; Supelco, St. Louis, USA) equipped with a guard column Supelguard $\left(4 \times 20 \mathrm{~mm}, 5 \mu \mathrm{m}\right.$, Supelco). The eluents, $50 \mathrm{mM} \mathrm{KH_{2 }} \mathrm{PO}_{4}$, $50 \mathrm{mM} \mathrm{K} \mathrm{K}_{2} \mathrm{HPO}_{4}, 4 \mathrm{mM}$ TBAB, and $10 \%$ methanol, adjusted to $\mathrm{pH} 6.0$ with $\mathrm{H}_{3} \mathrm{PO}_{4}$, were prepared in the day of use and filtered through a $0.22-\mu \mathrm{m}$ filter (Millipore). The methodology used was modified from the original protocol proposed by Kawamoto et al. (1998), for the best separation and reproducibility under ours conditions. The hydrolysis of ATP and generation of ADP and AMP was determinate incubating $2 \times 10^{7} \mathrm{cells} / \mathrm{ml}$ in a mixture containing $116 \mathrm{mM} \mathrm{NaCl}, 5.4 \mathrm{mM} \mathrm{KCl}, 5.5 \mathrm{mM}$ D-glucose, $50 \mathrm{mM}$ Hepes-Tris buffer, $\mathrm{pH} 7.2$, and $100 \mu \mathrm{M}$ ATP. After $5,15,30,45,60$, and $120 \mathrm{~min}$, aliquots of $200 \mu 1$ were taken and loaded in the system for the separation. The amount of nucleotides was calculated using the peak ratio area in the calibration graph. 


\subsection{Preparation of plasma membrane}

Promastigotes $\left(3.0 \times 10^{8}\right.$ cells $)$ at late $\log$ phase of growth $(72 \mathrm{~h})$ were harvested by centrifugation and washed three times in cold PBS. Plasma membrane was obtained as reported by Cohen et al. (1986), with some modifications. Briefly, parasites were mixed with glass beads and disrupted by abrasion for $10 \mathrm{~min}$ on ice bath. After grinding, $25 \mathrm{ml}$ of $10 \mathrm{mM}$ Hepes, pH 7.4, $400 \mathrm{mM}$ mannitol, $10 \mathrm{mM} \mathrm{KCl}$, $1 \mathrm{mM}$ magnesium acetate, $1 \mathrm{mM}$ PMSF, $10 \mu \mathrm{M}$ E-64 and $1 \mu \mathrm{M}$ pepstatin $\mathrm{A}$ were added to the mixture. The glass beads, unbroken cells and large cell debris (total homogenate) were removed by centrifugation at $1000 \mathrm{~g}$ for $15 \mathrm{~min}$ at $4^{\circ} \mathrm{C}$. The supernatant was centrifuged at $5000 \mathrm{~g}$ for $20 \mathrm{~min}$, at $16,000 \mathrm{~g}$ for $40 \mathrm{~min}$ and then at $105,000 \mathrm{~g}$ for $1 \mathrm{~h}$. The resulting pellet (total membrane) was resuspended in $150 \mathrm{mM} \mathrm{KCl}, 2 \mathrm{mM} \mathrm{MgCl} 2,1 \mathrm{mM}$ DTT and $75 \mathrm{mM}$ Hepes, $\mathrm{pH} 7.4$, and subsequently applied in a continuous density gradient of $18 \%$ Percoll in $0.25 \mathrm{M}$ sucrose and $12 \mathrm{mM}$ Tris$\mathrm{HCl}, \mathrm{pH}$ 7.4. After centrifugation at $40,000 \mathrm{~g}$ for $1 \mathrm{~h}$, the plasma membrane was obtained and kept at $-80^{\circ} \mathrm{C}$, for further analysis. Protein concentration of each fraction was determined by Lowry et al. (1951), using BSA as standard.

\subsection{Membrane solubilization}

The assay medium consisted of $12 \mathrm{mM}$ Tris- $\mathrm{HCl}, \mathrm{pH}$ $8.5,250 \mathrm{mM}$ sucrose, $20 \%$ glycerol and different concentrations of Triton X-100. The reaction was performed for $20 \mathrm{~min}$ at $4^{\circ} \mathrm{C}$ and started by the addition of plasma membrane fraction $(400 \mu \mathrm{g})$. The solubilized membrane was obtained after centrifugation at $100,000 \mathrm{~g}$ for $1 \mathrm{~h}$. EctoATPase activities were determined in the supernatant, as described below.

\subsection{3'-nucleotidade activity assay}

Protein fractions $(100 \mu \mathrm{g})$ were incubated with $50 \mathrm{mM}$ Hepes, pH 7.4, $5 \mathrm{mM}$ 3'-AMP, $1 \mathrm{mM}$ sodium vanadate, $10 \mathrm{mM}$ sodium azide, $1 \mathrm{mM}$ ammonium molybdate, and $10 \mathrm{mM} \mathrm{NaF}$ for $1 \mathrm{~h}$ at $25^{\circ} \mathrm{C}$. The reaction was stopped by the addition of $1 \mathrm{ml}$ of $0.2 \mathrm{~g} / \mathrm{ml}$ charcoal in $\mathrm{HCl}$. The test tubes were centrifuged at $1500 \mathrm{~g}$ for $10 \mathrm{~min}$. After centrifugation, phosphate was determined in the supernatant by Fiske and Subbarow method (Fiske and Subbarow, 1925).

\subsection{Ecto-ATPase activities measurement}

Intact cells were incubated for $1 \mathrm{~h}$ at $25^{\circ} \mathrm{C}$ in $0.5 \mathrm{ml}$ of a mixture containing, unless otherwise specified, $116 \mathrm{mM}$ $\mathrm{NaCl}, 5.4 \mathrm{mM} \mathrm{KCl}, 5.5 \mathrm{mM}$ D-glucose, $50 \mathrm{mM}$ Hepes-Tris buffer, pH 7.2, $5 \mathrm{mM} \mathrm{MgCl}, 5 \mathrm{mM} \mathrm{ATP}$, and $5.0 \times 10^{7}$ parasites $/ \mathrm{ml}$. In the case of protein fractions or purified plasma membrane, the following assay medium was used: $50 \mathrm{mM}$ Hepes-Tris buffer, $\mathrm{pH} 7.2,5 \mathrm{mM} \mathrm{MgCl}_{2}, 5 \mathrm{mM}$ ATP, and inhibitors for other nucleotide hydrolases, such as $1 \mathrm{mM}$ sodium vanadate, $10 \mathrm{mM}$ sodium azide, $1 \mathrm{mM}$ ammonium molybdate, and $10 \mathrm{mM} \mathrm{NaF}$. The ATPase activities were determined by measuring the hydrolysis of $\left[\gamma^{32} \mathrm{P}\right] \mathrm{ATP}$ $\left(10^{4} \mathrm{~Bq} / \mathrm{nmol}\right.$ ATP) (Berredo-Pinho et al., 2001). The experiments were started by the addition of living cells or protein fractions and stopped by the addition of $1 \mathrm{ml}$ of a cold mixture of $0.2 \mathrm{~g}$ charcoal in $1 \mathrm{ml} \mathrm{HCl}$. The test tubes were centrifuged at $1500 \mathrm{~g}$ for $10 \mathrm{~min}$ at $4{ }^{\circ} \mathrm{C}$. Aliquots $(0.5 \mathrm{ml})$ of the supernatants containing the released ${ }^{32} \mathrm{P}_{\mathrm{i}}$ were transferred to scintillation vials containing $10 \mathrm{ml}$ of scintillation fluid ( $2 \mathrm{~g}$ PPO in $1 \mathrm{~L}$ of toluene). The ATPase activities were calculated by subtracting the non-specific ATP hydrolysis measured in the absence of cells or protein fractions.

\subsection{Non-denaturing PAGE}

The solubilized plasma membrane $(100 \mu \mathrm{g})$ was applied in non-denaturing PAGE as described by Vasconcelos et al. (1996). After electrophoresis, the gels were washed several times with $5 \mathrm{mM} \mathrm{MgCl}_{2}, 1 \mathrm{mM}$ ammonium molybdate, $10 \mathrm{mM}$ azide, $1 \mathrm{mM}$ vanadate, and Hepes $25 \mathrm{mM}$, pH 7.2, and then incubated overnight in the same solution containing $5 \mathrm{mM}$ ATP. Ecto-ATPase activities were detected by malachite green method for $\mathrm{P}_{\mathrm{i}}$ detection (Zlotnick and Gottlieb, 1986).

\subsection{Immunocytochemical assay}

Promastigotes $\left(1.0 \times 10^{8}\right.$ cells $)$ at stationary phase of growth (96h) were washed twice in PBS, fixed in a solution containing $1 \%$ glutaraldehyde, $4 \%$ paraformaldehyde in $0.1 \mathrm{M}$ sodium cacodylate buffer, $\mathrm{pH} 7.2$, for $2 \mathrm{~h}$. Then, the parasites were washed in $0.1 \mathrm{M}$ cacodylate buffer and incubated for $2 \mathrm{~h}$ with a 1:50 dilution of the mouse monoclonal anti-CD39 antibody (Zymed Laboratories, Inc., San Franciso, CA) in blocking buffer (PBS, 3\% BSA). The parasites were then washed five times in blocking buffer and subsequently incubated in the presence of a secondary antibody (goat anti-mouse antibody) conjugated to colloidal gold $(10 \mathrm{~nm}$, Pelco International) at 1:40 dilution for $2 \mathrm{~h}$. Control was performed by following the same procedure but without primary antibody. Finally, the parasites were washed, dehydrated in acetone and embedded in Polybed epoxi resin (Polyscience). After $48 \mathrm{~h}$ at $60^{\circ} \mathrm{C}$, ultrathin sections were obtained and collected in grids (Pelco) and observed in a Zeiss 900 transmission electron microscope.

\subsection{Flow cytometry analysis}

Parasites $\left(5.0 \times 10^{6}\right.$ cells $)$ were fixed in $4 \%$ paraformaldehyde in PBS, pH 7.2, for $30 \mathrm{~min}$ followed by several washes in the same buffer. These fixed cells maintained their morphological integrity, as verified by light microscopic observation. They were incubated for $2 \mathrm{~h}$ with different anti-E-NTPDase antibodies: mouse monoclonal anti-human CD39 (Zymed Laboratories, Inc., San Franciso, CA), rabbit polyclonal antihuman NTPDase2 (Kw2- $\mathrm{I}_{5}$ and $\left.\mathrm{Kw} 3-\mathrm{I}_{5}\right)$ and anti-mouse NTPDase2 (mN2-35) (kindly provided by Dr. Jean Sévigny, 
Université Laval, Sainte-Foy, Québec, Canada) and then incubated for an additional hour with a 1:100 dilution of fluorescein isothiocyanate (FITC)-labeled goat anti-rabbit or anti-mouse (as specified) IgG. These cells were examined in an EPICS ELITE flow cytometer (Coulter Electronics, Hialeah, Fla.), equipped with a $15 \mathrm{~mW}$ argon laser emitting at $488 \mathrm{~nm}$. Untreated cells were used as controls to determine autofluorescence. Each experimental population was then mapped by using a two-parameter histogram of forwardangle light scatter versus side scatter. The mapped population $(n=10,000)$ was then analyzed for log green fluorescence by using a single-parameter histogram.

\subsection{Western blot analysis}

Protein extracts were separated in 10\% SDS-PAGE and the polypeptides electrophoretically transferred at $4{ }^{\circ} \mathrm{C}$ at $100 \mathrm{~V} / 300 \mathrm{~mA}$ for $2 \mathrm{~h}$ to a nitrocellulose membrane. The membrane was blocked in 5\% non-fat dried milk in TBS $(150 \mathrm{mM} \mathrm{NaCl} ; 10 \mathrm{mM}$ Tris, $\mathrm{pH} 7.4)$ containing $0.1 \%$ Tween 20 (TBS/Tween), overnight at $4{ }^{\circ} \mathrm{C}$. Then, membranes were washed three times $(10 \mathrm{~min}$ each) with TBS/ Tween and incubated with rabbit anti-gp63 antibody (kindly provided by Dr. Kwang-Poo Chang, University of Health Sciences, Chicago Medical School, USA) or with the different anti-E-NTPDase antibodies listed above, at 1:250 dilution for $2 \mathrm{~h}$. The secondary antibody used was peroxidase-conjugated goat anti-rabbit at 1:2500. Immunoblots were exposed to X-ray film after reaction with ECL reagents for chemiluminescence. The films were scanned and digitally processed. The densitometric analysis was performed with the use of the Kodak Digital Science EDAS 120 software, as previously described (Soares et al., 2003).

\subsection{Mouse peritoneal macrophages and interaction}

Peritoneal macrophages from female Swiss mice (6-8 weeks old) were collected in cold RPMI medium (Gibco BRL, Gaithersburg, USA) and allowed to adhere to coverslips placed in 24-well tissue culture plates for $30 \mathrm{~min}$ at $37{ }^{\circ} \mathrm{C}$, in a $5 \% \mathrm{CO}_{2}$ atmosphere. Non-adherent cells were removed and the adhering macrophages washed twice with RPMI and cultured for $24 \mathrm{~h}$ in the same culture medium. Three day-old promastigotes grown in the absence or presence of $5 \mathrm{mM}$ adenosine were collected by centrifugation, washed three times in PBS, and then added to the macrophage culture well plates. Alternatively, parasites were pretreated for $1 \mathrm{~h}$ with anti-NTPDase antibodies (anti-Kw2- $\mathrm{I}_{5}$ and anti-Kw3- $\mathrm{I}_{5}$ ) or with an irrelevant IgG at 1:500 dilution. The parasite-macrophage interaction studies were performed at $37^{\circ} \mathrm{C}$ for $1 \mathrm{~h}$, at a ratio of 10 promastigotes to 1 macrophage. After the interaction, the coverslips were fixed in methanol and Giemsa-stained, and the percentage of infected macrophages was determined by counting 200 cells in triplicate coverslips. The association indices were determined by multiplying the percentage of infected macrophages by the mean number of parasites per infected cell.

\subsection{Statistical analysis}

All experiments were performed in triplicate, with similar results obtained in at least three separate experiments. The data were analyzed statistically by means of Student's $t$ test. $P$ values of 0.05 or less were considered significant. The data are expressed as means \pm standard error.

\section{Results and discussion}

Nucleotides may act as extracellular signaling molecules in virtually all cells. In particular, extracellular ATP is involved in a large variety of physiological and pathological functions (Haskó et al., 2002). There are several types of surface-located enzymes that have the potential to hydrolyze extracellular nucleotides (Zimmermann, 2001). In a previous work, we described biochemical characteristics of different enzymatic activities, including ecto-ATPase, ectoADPase, and ecto-5'-nucleotidase, on the cell surface of $L$. amazonensis promastigote forms (Berredo-Pinho et al., 2001). However, little is known about the adenosine generation during ATP hydrolysis by this pathogenic trypanosomatid. Therefore, using ion-pair reverse-phase HPLC, we identified and quantified the nucleotides sequentially generated from the ATP degradation by the surface-located enzymes in promastigotes of $L$. amazonensis. The concentration of ATP decreased by approximately $90 \%$ in the first $10 \mathrm{~min}$ of reaction, generating $78.8 \pm 1.4 \mu \mathrm{M}$ of ADP (Fig. 1A). Then, in the course of $45 \mathrm{~min}$, the ADP concentration diminished significantly and reached $26.07 \pm 1.67 \mu \mathrm{M}$. The highest AMP concentration $(24.29 \pm 2.83 \mu \mathrm{M})$ was obtained in $15 \mathrm{~min}$, which was accompanied by its hydrolysis yielding adenosine. The ATP molecules were totally hydrolyzed within the first $60 \mathrm{~min}$ of reaction. After $120 \mathrm{~min}$, approximately $82 \%$ of the initial ATP concentration was converted in adenosine (Fig. 1A). A possible role for the ecto-ATPase of $L$. amazonensis could be the degradation of nucleosides in the surroundings of the parasite, since this parasite lack the ability to synthesize purines de novo, and their growth and survival is dependent upon the scavenging of these essential nutrients and their derivatives from the host (Steiger and Steiger, 1977).

We used the anti-CD39 antibody to localize the ecto-ATPase in L. amazonensis promastigotes by immunoelectron microscopic observation (Figs. 1B and C). Gold particles were observed unequally distributed on the cytoplasmic membrane of the parasites (Figs. 1B and C). Similar ecto-ATPase distribution pattern was evidenced in Crithidia deanei (Dos Passos Lemos et al., 2002). In contrast, the parasites treated solely with the secondary antibody, used as a control, did not present any positive reaction (data not shown). The ecto-localization of $L$. amazonensis ecto-nucleoside triphosphate diphosphohydrolase activities confirms that this parasite possesses mechanisms capable of hydrolyzing nucleoside di- and triphosphates present in the extracellular medium. 

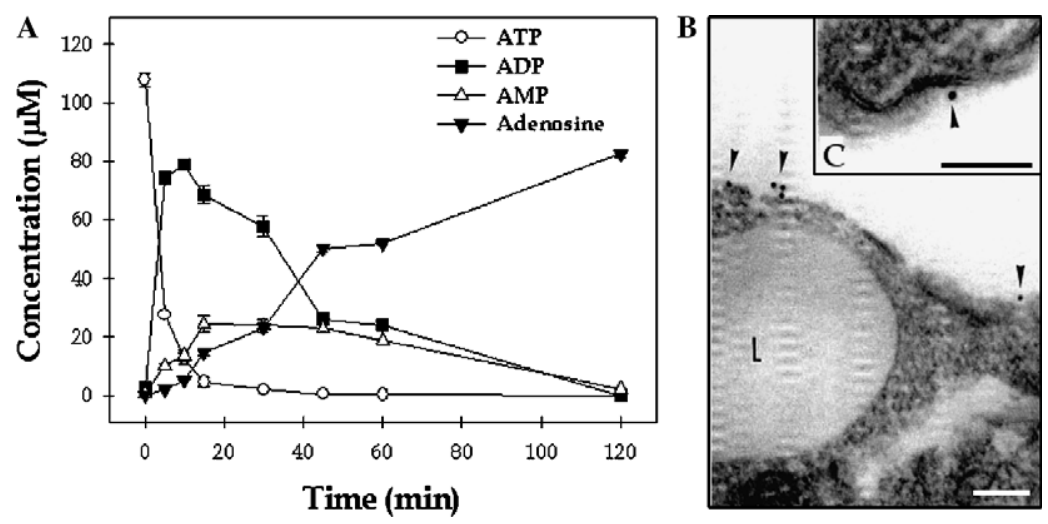

Fig. 1. (A) Analysis of ATP hydrolysis by promastigotes of Leishmania amazonensis. The parasites $\left(2.0 \times 10^{8}\right.$ cell $\left./ \mathrm{ml}\right)$ were incubated for each indicated period of time at $30^{\circ} \mathrm{C}$ in the presence of $100 \mu \mathrm{M}$ ATP. The amount of nucleotides (ATP, ADP, and AMP) and nucleoside (adenosine) was determined by HPLC, as described in Section 2. Data are means \pm SE of three independent determinations. (B and C) Immunocytochemical localization of NTPDase from L. amazonensis. Promastigotes were incubated in the presence of anti-CD39 antibody (at 1:50 dilution) for $2 \mathrm{~h}$, followed by incubation with anti-IgG conjugated with gold particles. The arrowheads show the gold particles unequally distributed on the external surface of the parasite plasma membrane. Note in (C) an augmentation of (B) showing the intact parasite surface. Bars, $5 \mu \mathrm{m}$.

We also tested a panel of four different antibodies raised against NTPDase family members, to verify the homology among these enzymes, and the results were analyzed by flow cytometry (Fig. 2). The anti-human NTPDase2 antibody (designated as anti-Kw2-I ${ }_{5}$ ) showed the most powerful reaction with the cell surface of $L$. amazonensis, followed by anti-Kw3-I $\mathrm{I}_{5}$ (that recognizes human NTPDase2), anti-CD39, and anti-mN2-35 (both recognize mouse NTPDase2) (Fig. 2). The E-NTPDase family comprehends eight different members (Zimmermann, 2001). These individual members may differ regarding sequence identity; however, five highly conserved sequence domains within extracellular region (apyrase conserved regions) are shared by all sequences (Schulte am Esch II et al., 1999).

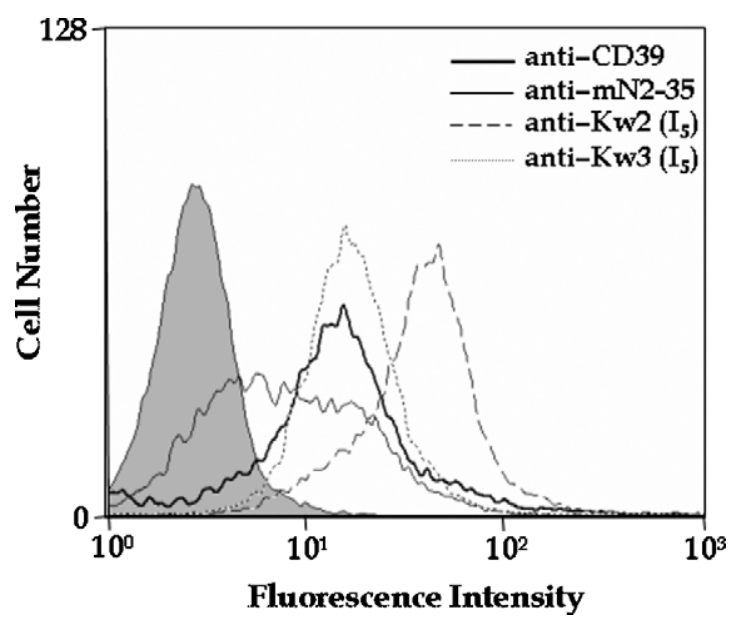

Fig. 2. Flow cytometry analysis of Leishmania amazonensis incubated with different anti-NTPDase antibodies. Parasites were grown in Warren's medium for $72 \mathrm{~h}$ at $22{ }^{\circ} \mathrm{C}$. Then, promastigotes were harvested, fixed in paraformaldehyde, and sequentially incubated for $2 \mathrm{~h}$ in the absence (gray curve) or in the presence of different anti-NTPDase antibodies (antiCD39, anti-Kw2 $\left(\mathrm{I}_{5}\right)$, anti-Kw3 $\left(\mathrm{I}_{5}\right)$, and anti-mN2-35) and then with FITC-IgG. Analysis of 10,000 cells in each system is shown.
Enzymes homologue to the NTPDase family might play a role in endoparasites by de-activating defense responses of the host that involve ATP or ADP on the surface of the cells, such as platelet activation cytotoxicity and cytolytic T-lymphocyte reactivity (Aguiar Mattos et al., 2001; Vasconcelos et al., 1996).

We obtained a plasma membrane-rich fraction through differential centrifugation, to better characterize the ectoNTPDase activities expressed in promastigotes of $L$. amazonensis. During the cell fractionation, we accompanied the membrane enrichment through SDS-PAGE and by analyzing two different markers: the $3^{\prime}$-nucleotidase activity, which is a trypanosomatid specific surface-located enzyme (Dwyer and Gottlieb, 1984), and leishmanolysin that is a major surface protein expressed on the cell surface of all Leishmania species (Yao et al., 2003). Our results showed that the quantitative measurement of the 3 '-nucleotidase activity present on the plasma membrane fraction increased 4.2-fold in comparison to cellular homogenate (Fig. 3A). Similarly, Western blotting utilizing anti-gp63 antibody (Fig. 3B, inset) and densitometrical analysis (Fig. 3B) demonstrated a strong reaction with the plasma membrane fraction, in comparison with the cellular homogenate and total membrane. The polypeptide profiles of these three studied fractions were also showed in the inset of Fig. 3A.

Some members of the E-NTPDase family are sensitive to detergents, which make it difficult their solubilization in an active state (Plesner, 1995). The effect of increasing concentration of Triton X-100 on plasma membrane fraction of $L$. amazonensis was also tested and presented in the Fig. 4. Interestingly, the low detergent/protein ratio ( 0.25 and 0.5$)$ promoted activation in the ecto-NTPDase activities of $L$. amazonensis, while detergent/protein ratio equal or superior to 1 did not significantly alter the enzymatic behavior (Fig. 4). One explanation for this apparent activation of the ecto-ATPase activity at low detergent/protein ratio might be the permeabilization of some vesicles present in the 
A

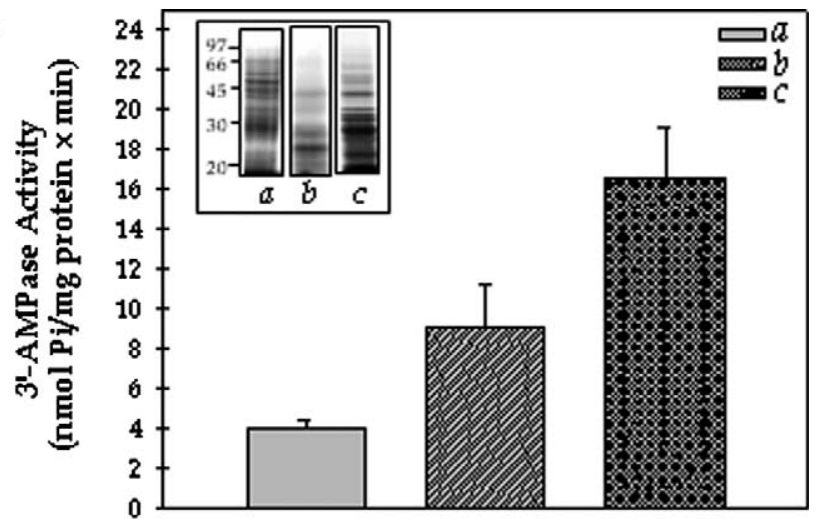

B

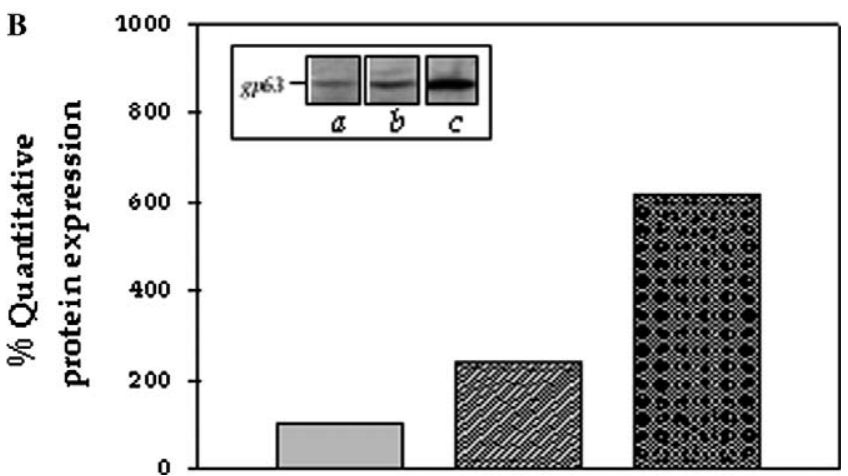

Fig. 3. Analysis of the Leishmania amazonensis membrane-enrichment process. Initially promastigote cells were submitted to differential centrifugation and three distinct fractions were obtained: total homogenate (a), total membrane (b), and plasma membrane (c) (insets). Then, two distinct parasite surface markers were analyzed: 3'-AMPase activities (A) and gp63 protein (B). The polypeptide content of each fraction was separated on $10 \%$ SDS-PAGE (inset in A) and the gp63 protein level was examined by Western blotting using a polyclonal anti-gp63 antibody (inset in B) and then quantified by densitometric analysis (B). Notes: (1) the variation of protein amount was calculated taking the amount in total homogenate as reference values $(100 \%)$, and the percentage values represent means of three independent measurements; (2) band areas in the inset of (B) were determined by repeating the densitometrical process three times, to diminish the probability of errors in these estimations; (3) the numbers on the left in the inset of (A) indicate the relative molecular mass markers expressed in kilodaltons $(\mathrm{kDa})$.

membrane preparation (Benain et al., 1991). One of the major problems in studies of soluble NTPDase is the maintenance of enzyme activity. Moller et al. (1982) concluded that several factors, such as aggregational state of the ATPase, type of detergent, and protein concentration, are important for enzyme stability. In our case, after the solubilization, a decrease of water activity of the medium, promoted by the addition of detergent, may have stabilized the parasite enzyme. The polypeptide content of the solubilized membrane fraction was applied on 10\% SDS-PAGE and several polypeptides were observed with apparent molecular masses varying from 55 to $20 \mathrm{kDa}$ (Fig. 4, inset A, lane a). This solubilized fraction was also submitted to electrophoresis in non-denaturing conditions, followed by the enzymatic activities detection using $5 \mathrm{mM}$ ATP as substrate, which showed a single reactive band (Fig. 4, inset A, lane $\mathrm{b}$ ). Western blotting analysis showed that the four

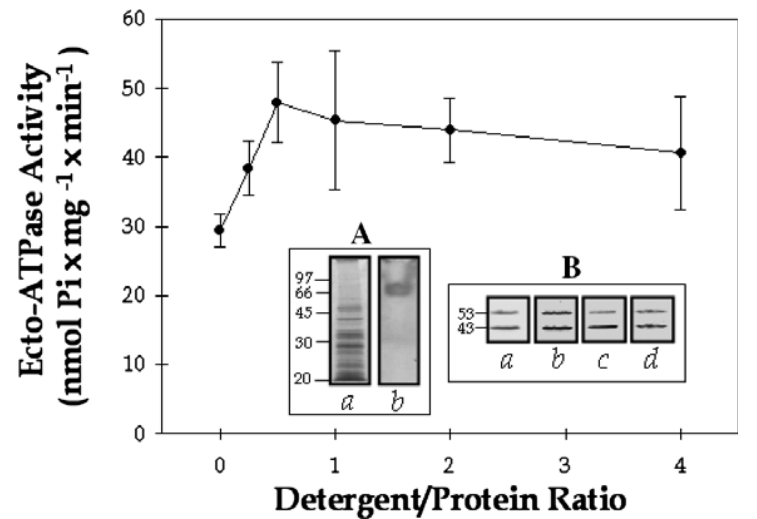

Fig. 4. Effect of Triton X-100 on the ecto-ATPase activities of Leishmania amazonensis. Different concentrations of Triton X-100 were added to the plasma membrane fraction and then the ATPase activities was measured as described in Section 2. Insets: (A) polypeptide profile of the plasma membrane fraction solubilized in Triton X-100 (1:2 protein:detergent ratio) was shown in (a), as well as the ATPase activities in non-denaturing gel, after separation of the proteins by PAGE, using the malachite green method in (b); (B) immunoblotting of polypeptides present in the plasma membrane fraction of $L$. amazonensis against different anti-NTPDase antibodies: anti-CD39 (a), anti-mN2-35 (b), anti-Kw2 $\left(\mathrm{I}_{5}\right)$ (c), and antiKw3 $\left(I_{5}\right)($ d) at 1:1000 dilution. The numbers on the left indicate relative molecular mass of polypeptides expressed in kilodaltons.

different E-NTPDase antibodies recognized two major polypeptides of 53 and $43 \mathrm{kDa}$ (Fig. 4, inset B). Similarly, in Trypanosoma cruzi, a $58 \mathrm{kDa}$ polypeptide was immunoprecipitated with an anti-NTPDase antibody (Fietto et al., 2004).

Ecto-ATPases are enzymes that exhibit divalent cationdependence for their fully activity (Meyer-Fernandes, 2002; Plesner, 1995). In L. amazonensis, it was shown that the addition of $\mathrm{MgCl}_{2}$ to the extracellular medium increased the ecto-ATPase activity of the intact cells, in a dose-dependent manner, reaching the maximum activity with $5 \mathrm{mM}$ $\mathrm{MgCl}_{2}$ (Berredo-Pinho et al., 2001). Here, we confirmed our previous result (Fig. 5A) and we also showed the requirement of $\mathrm{Mg}^{2+}$ for the ATPase activities present in both plasma membrane and solubilized membrane fractions of L. amazonensis (Figs. 5B and C). The low ATPase activity measured in the absence of any divalent metal $(1 \mathrm{mM}$ EDTA) was also observed in Entamoeba histolytica (Barros et al., 2000).

The composition of the cell surface changes dramatically during the life cycle of Leishmania (Naderer et al., 2004). Accordingly, we analyzed if the ecto-NTPDase activities were modulated during the growth in vitro of L. amazonensis promastigotes for 24-96h, by quantitative measurement and flow cytometry. Our results showed an accentuated reduction on the ecto-NTPDase activity levels during the $96 \mathrm{~h}$ of growth in culture medium (Fig. 6A), related to decrease of expression levels of the enzyme in the surface as was determined by FACS (Fig. 6B). The leishmanial ectoNTPDase activities were highest when cells were in the logarithmic growth phase (24-48h), suggesting that this transitory increase occurs as the cells prepare for cell 


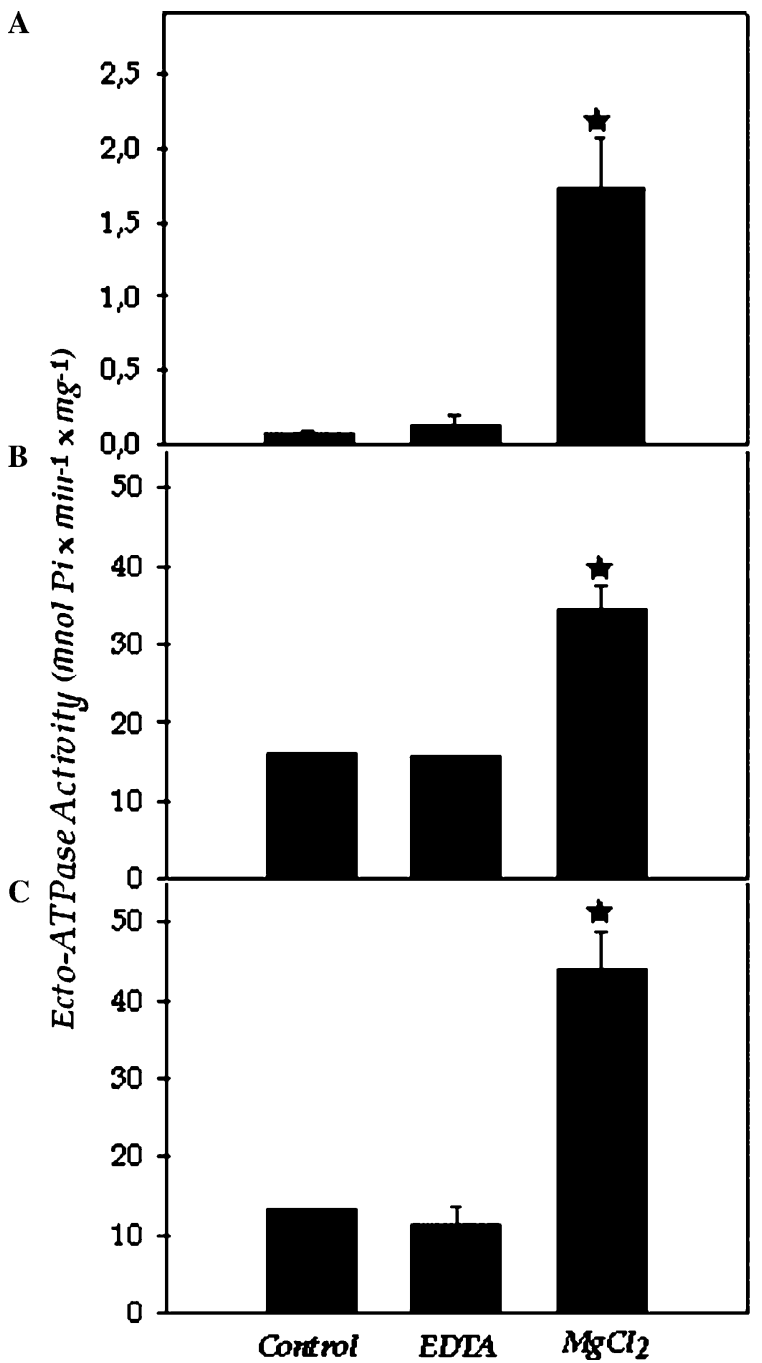

Fig. 5. Influence of magnesium on the ATPase activities of Leishmania amazonensis. Intact promastigote cells (A), plasma membrane fraction (B) and Triton X-100-solubilized plasma membrane (C) were incubated for $1 \mathrm{~h}$ at $30^{\circ} \mathrm{C}$ in a reaction medium containing $50 \mathrm{mM}$ Hepes-Tris buffer, pH 7.2, $116 \mathrm{mM} \mathrm{NaCl}, 5.4 \mathrm{mM} \mathrm{KCl}, 5.5 \mathrm{mM}$ D-glucose, and $5 \mathrm{mM}$ TrisATP $\left[\gamma_{-}{ }^{32} \mathrm{P}\right]$ ATP (sp act $10^{4} \mathrm{~Bq} / \mathrm{nmol}$ ATP) in the absence (control) or in the presence of $1.0 \mathrm{mM}$ EDTA or $5.0 \mathrm{mM} \mathrm{MgCl}_{2}$. Data are means $\pm \mathrm{SE}$ of three independent determinations with different cell suspensions. Asterisks indicate $P<0.05$ between the control and magnesium dependent ATPase activities.

division and must acquire all the necessary nutrients needed for the synthetic events in this process.

Studies undertaken over the last decade showed that the composition of the complex glycocalyx surface changes dramatically as promastigotes differentiate into amastigotes (reviewed in Descoteaux and Turco, 1999). Interestingly, the amastigotes expressed on their surface an exacerbate ecto-ATPase activities $\left(404.2 \mathrm{nmol} \mathrm{P}_{\mathrm{i}} \times \mathrm{h}^{-1}\right.$ $\times 10^{7}$ cells $)$ in comparison to promastigotes $(29.2 \mathrm{nmol}$ $\mathrm{P}_{\mathrm{i}} \times \mathrm{h}^{-1} \times 10^{7}$ cells) (Fig. 7). Similarly, the infective stages of T. cruzi (trypomastigotes and amastigotes) had much higher $\mathrm{Mg}^{2+}$-dependent ecto-ATPase activity than the noninfective epimastigotes, suggesting that this ecto-enzyme of $T$. cruzi could be considered a virulence marker (Meyer-
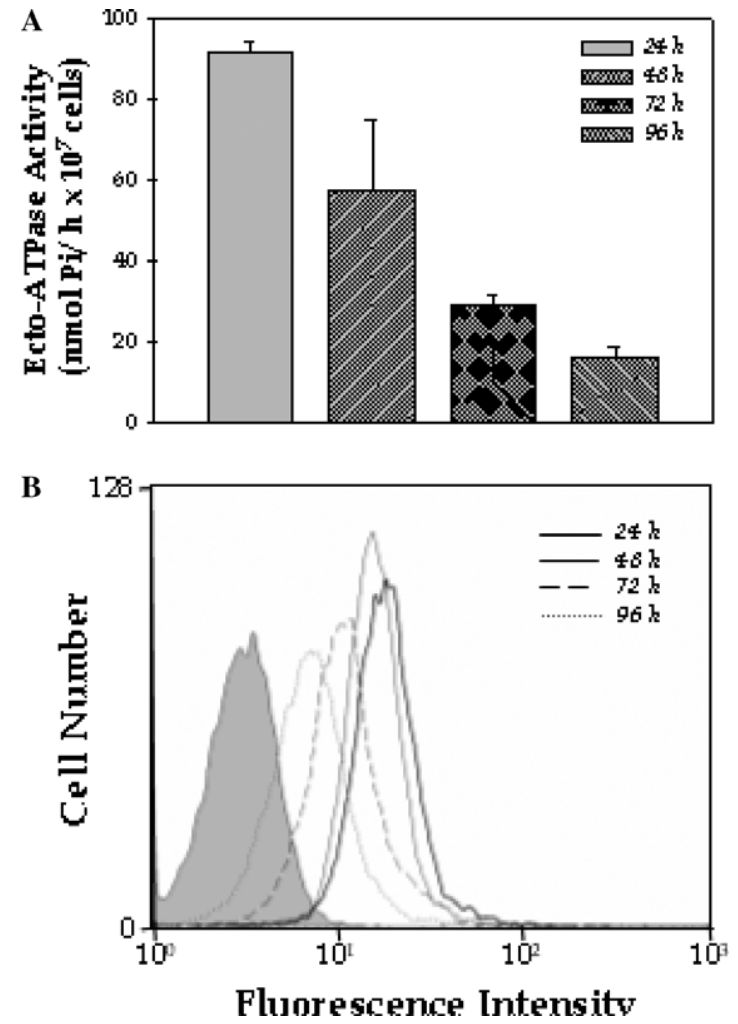

Fig. 6. Analysis of the ecto-ATPase activities in promastigotes of Leishmania amazonensis during the $96 \mathrm{~h}$ of growth in vitro. (A) Quantitative measurement of the ATPase activities and (B) flow cytometry analysis using the anti-CD39 antibody. Note: gray curve represents the autofluorescence of promastigotes.

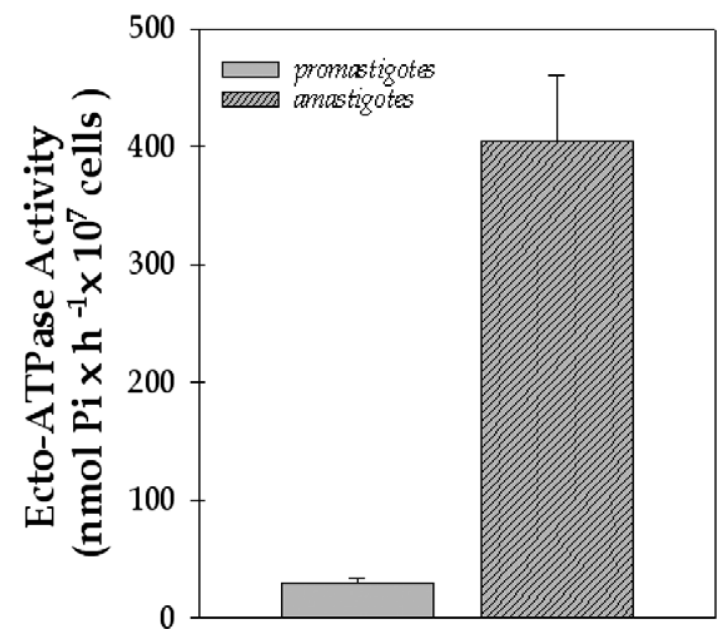

Fig. 7. Ecto-ATPase activities in different evolutive stages of Leishmania amazonensis. Parasites (promastigote and amastigote forms) at late log phase of growth $\left(72 \mathrm{~h}\right.$ ) were incubated for $1 \mathrm{~h}$ at $30^{\circ} \mathrm{C}$ in the same reaction medium as that described in the Section 2. Data are means $\pm \mathrm{SE}$ of three determinations with different cell suspensions.

Fernandes et al., 2004). Collectively, these results suggest the possible participation of ecto-ATPases in the escape mechanisms of the trypanosomatids against the host response. Additionally, this class of hydrolytic enzymes could provide the nutritional requirements to the amasti- 
gote stage inside the mammalian macrophages. In this context, the involvement of ecto-ATPases in cell proliferation has been proposed. For instance, cellular growth of $L$. amazonensis promastigote forms was stimulated by more than 2 -fold by $5 \mathrm{mM}$ AMP, ADP or ATP, and by more than 5fold by $5 \mathrm{mM}$ adenosine (Berredo-Pinho et al., 2001). Conversely, adenosine was capable to induce a reduction on the ecto-ATPase recognition in promastigotes in a dose-dependent manner, as observed by flow cytometry (Fig. 8).

The purine adenosine is now considered an important stress hormone that is released in excessive amounts in the vicinity of immune cells, during both systemic and cellular stress (Haskó et al., 2002; Haskó and Szabó, 1998). For example, adenosine attenuates macrophage antibacterial activity by suppressing the production of superoxide (Edwards et al., 1994) and nitric oxide (Xaus et al., 1999), both of which are essential in killing intracellular obligatory microorganisms. Therefore, the adenosine generation by amastigotes inside the macrophages could also help the parasites to escape the host cell immune response. Here we show that adenosine $(5 \mathrm{mM})$ promoted a significant diminishing on the association index between promastigotes of $L$. amazonensis and mouse peritoneal macrophages (Fig. 9). Similarly, the pretreatment of promastigotes with the anti-NTPDase antibodies also significantly reduced the interaction process (Fig. 9). Conversely, using an irrelevant $\mathrm{IgG}$, the interaction process was very similar to the obtained with non-treated parasites (Fig. 9). Collectively, these results suggest that the ecto-ATPase may directly or indirectly play a role on the adhesion process between $L$. amazonensis and macrophages. Previous studies suggested a correlation between parasite ecto-ATP-hydrolysis and virulence, intracellular survival and adhesion, respectively (Asai et al., 1995; Barros et al., 2000; Berredo-Pinho et al., 2001; Jesus et al., 2002).

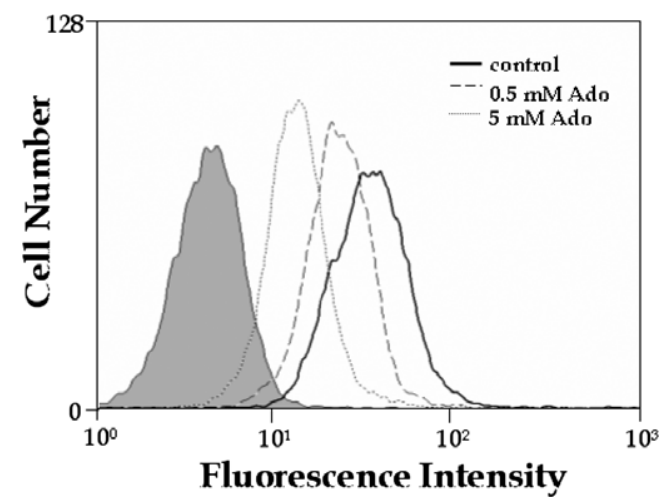

Fig. 8. Flow cytometry analysis using the anti-CD39 antibody: effect of adenosine on the quantification of ecto-ATPase enzyme on the surface of Leishmania amazonensis. Promastigote cells were cultivated in Warren's medium at $22{ }^{\circ} \mathrm{C}$ for $72 \mathrm{~h}$ in the absence (control) or in the presence of 0.5 and $5 \mathrm{mM}$ adenosine (Ado). After, cells were harvested and processed by flow cytometry analysis as described in the legend of Fig. 2. Gray curve represents the autofluorescence of promastigotes.

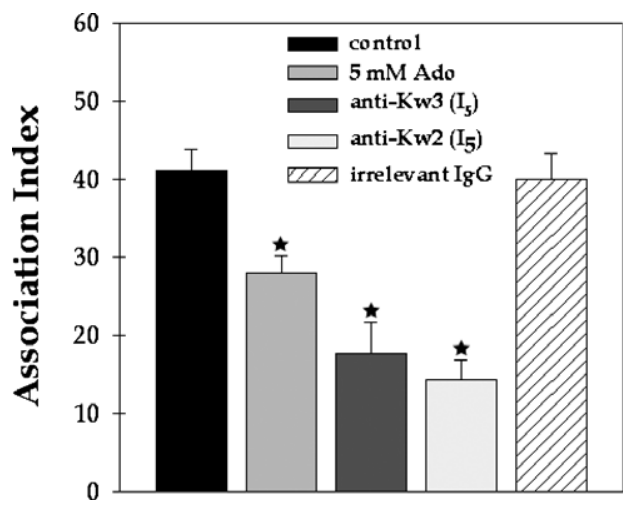

Fig. 9. Influence of adenosine and anti-NTPDase antibodies on the cellular interaction between promastigotes of Leishmania amazonensis and mouse peritoneal macrophages. Parasites were grown in the absence (control) or in the presence of $5 \mathrm{mM}$ adenosine (Ado) for $72 \mathrm{~h}$. Alternatively, control parasites were pretreated for $1 \mathrm{~h}$ with the anti-NTPDase antibodies (anti-Kw3-I ${ }_{5}$ or anti-Kw2-I ${ }_{5}$ ) or with an irrelevant IgG at 1:500 dilution. The interaction process was performed as described in the Section 2. Each bar represents the means \pm standard error of at least three independent experiments performed in triplicate. Asterisks denote significant difference $(P<0.05)$ in relation to the control system.

Ecto-NTPDase and other nucleotidases on cell membranes are known to exert their functions working coordinately, hydrolyzing nucleotides in order to generate nucleosides. The presence of an ecto-ATPase belonging to the NTPDase family in promastigotes of L. amazonensis is strongly suggested in this work. Here, we highly suggested the involvement of this NTPDase on cellular differentiation of $L$. amazonensis, an essential step during its life cycle. Finally, we also demonstrated that adenosine induced a significant diminishing both in the ecto-ATPase activities and in the interaction of promastigote forms and mouse peritoneal macrophages. Currently, we are investigating this last interesting phenomenon, to elucidate the function of NTPDase and adenosine in this essential process.

\section{Acknowledgments}

We thank Fabiano Ferreira Esteves and Bianca Alcântara da Silva for technical assistance. This study was supported by grants from Conselho Nacional de Desenvolvimento Científico e Tecnológico (CNPq), Coordenação de Aperfeiçoamento de Pessoal de Nível Superior (CAPES), Financiadora de Estudos e Projetos (FINEP), Fundação de Amparo à Pesquisa do Estado do Rio de Janeiro (FAPERJ), Fundação Universitária José Bonifácio (FUJB) and Programa de Apoio a Núcleos de Excelência (PRONEX).

\section{References}

Aguiar Mattos, J.A., Borges, F.P., Tasca, T., Bogo, M.R., De Carli, G.A., da Graça Fauth, M., Dias, R.D., Bonan, C.D., 2001. Characterization of an ATP diphosphohydrolase (Apyrase, EC 3.6.1.5) 
activity in Trichomonas vaginalis. International Journal of Parasitology 31, 770-775.

Alves, C.R., Côrte-Real, S., Bourguignon, S.C., Chaves, C.S., Saraiva, E.M.B., 2005. Leishmania amazonensis: early proteinase activities during promastigote-amastigote differentiation in vitro. Experimental Parasitology 109, 38-48.

Alves-Ferreira, M., Dutra, P.M., Lopes, A.H., Ferreira-Pereira, A., Scofano, H.M., Meyer-Fernandes, J.R., 2003. Magnesium-dependent ectoATP diphosphohydrolase activity in Herpetomonas muscarum muscarum. Current Microbiology 47, 265-271.

Asai, T., Miura, S., Sibley, L.D., Okabayashi, H., Takeuchi, T., 1995. Biochemical and molecular characterization of nucleoside triphosphate hydrolase isozymes from the parasitic protozoan Toxoplasma gondii. Journal of Biological Chemistry 270 (19), 11391-11397.

Barral, A., Pedral-Sampaio, D., Grimaldi Junior, G., Momen, H., McMahon-Pratt, D., Ribeiro de Jesus, A., Almeida, R., Badaro, M., BarralNeto, M., Carvalho, E.M., Johnson Jr., W.D., 1991. Leishmaniasis in Bahia, Brazil: evidence that Leishmania amazonensis produces a wide spectrum of clinical disease. The American Journal of Tropical Medicine and Hygiene 44, 536-546.

Barros, F.S., De Menezes, L.F., Pinheiro, A.A.S., Silva, E.F., Lopes, A.H.C.S., De Souza, W., Meyer-Fernandes, J.R., 2000. Ectonucleotide diphosphohydrolase activities in Entamoeba histolytica. Archives of Biochemistry Biophysics 375, 304-314.

Benain, G., Losada, S., Gadelha, F.R., Docampo, R., 1991. A calmodulinactivated $\left(\mathrm{Ca}^{2+}-\mathrm{Mg}^{2+}\right)$ ATPase is involved in $\mathrm{Ca}^{2+}$ transport by plasma membrane vesicles from Trypanosoma cruzi. Biochemical Journal 280, 715-720.

Berredo-Pinho, M., Peres-Sampaio, C.E., Chrispim, P.P.M., BelmontFirpo, R., Lemos, A.P., Martiny, A., Vannier-Santos, M.A., Meyer-Fernandes, J.R., 2001. A Mg-dependent ecto-ATPase in Leishmania amazonensis and its possible role in adenosine acquisition and virulence. Archives of Biochemistry Biophysics 391, 16-24.

Bisaggio, D.F.R., Peres-Sampaio, C.E., Meyer-Fernandes, J.R., Souto-Padrón, T., 2003. Ecto-ATPase activity on the surface of Trypanosoma cruzi and its possible role in the parasite-host cell interaction. Parasitology Research 91, 273-282.

Cohen, B.E., Ramos, H., Gamargo, M., Urbina, J., 1986. The water and ionic permeability induced by polyene antibiotics across plasma membrane vesicles from Leishmania sp. Biochimica et Biophysica Acta 860, $57-65$.

Convit, J., Pinardi, M.E., Rondon, A.J., 1972. Diffuse cutaneous leishmaniasis: a disease due to an immunological defect of the host. Transaction of the Royal Society of Tropical Medicine and Hygiene 66, 603-610.

Descoteaux, A., Turco, S.J., 1999. Glycoconjugates in Leishmania infectivity. Biochimica et Biophysica Acta 1455, 341-352.

Dombrowski, K.K.Y., Brewer, K.A., Kapp, J.A., 1998. Ecto-ATPase: an activation marker necessary for effector cell function. Immunology Review 161, 111-118.

Dos Passos Lemos, A., Pinheiro, A.A.S., Berrêdo-Pinho, M., Fonseca de Souza, A.L., Motta, M.C.M., De Souza, W., Meyer-Fernandes, J.R., 2002. Ectonucleotide diphosphohydrolase activity in Crithidia deanei. Parasitology Research 88, 905-911.

Dwyer, D.M., Gottlieb, M., 1984. Surface membrane localization of 3'and $5^{\prime}$-nucleotidase activities in Leishmania donovani promastigotes. Molecular and Biochemical Parasitology 10, 139-150.

Edwards III, C.K., Watts, L.M., Parmely, M.J., Linnik, M.D., Long, R.E., Borcherding, D.R., 1994. Effect of the carbocyclic nucleoside analogue MDL 201,112 on inhibition of interferon- $\gamma$-induced priming of Lewis (LEW/N) rat macrophages for enhanced respiratory burst and MHC class II $\mathrm{Ia}^{+}$antigen expression. Journal of Leukocyte Biology $56,133-144$.

Fietto, J.L.R., DeMarco, R., Nascimento, I.P., Castro, I.M., Carvalho, T.M.U., De Souza, W., Bahia, M.T., Alves, M.J.M., Verjovski-Almeida, S., 2004. Characterization and immunolocalization of an NTP diphosphohydrolase of Trypanosoma cruzi. Biochemichal and Biopysical Research Communication 316, 454-460.
Fiske, C.H., Subbarow, Y., 1925. The colorimetric determination of phosphorous. Journal of Biological Chemistry 66, 375-400.

Haskó, G., Deitch, E.A., Szabó, C., Németh, Z.H., Vizi, E.S., 2002. Adenosine: a potential mediator of immunosuppression in multiple organ failure. Current Opinion in Pharmacology 2, 440-444.

Haskó, G., Szabó, C., 1998. Regulation of cytokine and chemokine production by transmitters and co-transmitters of the autonomic nervous system. Biochemical Pharmacology 56, 1079-1087.

Herwaldt, B.L., 1999. Leishmaniasis. Lancet 354, 1191-1199.

Jesus, J.B., Lopes, A.H.C.S., Meyer-Fernandes, J.R., 2002. Characterization of an ecto-ATPase of Tritrichomonas foetus. Veterinary Parasitology $103,29-42$.

Kawamoto, Y., Shinozuka, K., Kunitomo, M., Haginaka, J., 1998. Determination of ATP and its metabolites released from rat caudal artery by isocratic ion-pair reversed-phase high-performance liquid chromatography. Analytical Biochemistry 262, 33-38.

Knowles, A.F., Chiang, W.C., 2003. Enzymatic and transcriptional regulation of human ecto-ATPase/E-NTPDase 2. Archives of Biochemistry and Biophysics 418, 217-227.

Lowry, O.H., Rosebrough, N.J., Farr, A.L., Randall, R.J., 1951. Protein measurement with the folin phenol reagent. Journal of Biological Chemistry 193, 265-275.

Meyer-Fernandes, J.R., 2002. Ecto-ATPases in protozoa parasites: looking for a function. Parasitology International 51, 299-303.

Meyer-Fernandes, J.R., Dutra, P.M.L., Rodrigues, C.O., Saad-Nehme, J., Lopes, A.H.C.S., 1997. Mg-dependent ecto-ATPase activity in Leishmania tropica. Archives of Biochemistry and Biophysics 341, $40-46$.

Meyer-Fernandes, J.R., Saad-Nehme, J., Peres-Sampaio, C.E., BelmontFirpo, R., Bisaggio, D.F.R., Couto, L.C., Fonseca de Souza, A.L., Lopes, A.H.S.C., Souto-Padrón, T., 2004. A Mg-dependent ecto-ATPase is increased in the infective stages of Trypanosoma cruzi. Parasitology Research 93, 41-50.

Moller, J.V., Andersen, J.P., le Maire, M., 1982. The sarcoplasmic reticulum $\mathrm{Ca}^{2+}$-ATPase. Molecular and Cellular Biochemistry 42, 83-107.

Mottram, J.C., Coombs, G.H., Alexander, J., 2004. Cysteine peptidases as virulence factors of Leishmania.. Current Opinion in Microbiology 7, 375-381.

Naderer, T., Vince, J.E., McConville, M.J., 2004. Surface determinants of Leishmania parasites and their role in infectivity in the mammalian host. Current Molecular Medicine 4, 649-665.

Nakaar, V., Beckers, C.J.M., Polotsky, V., Joiner, K.A., 1998. Basis for substrate specificity of the Toxoplasma gondii nucleoside triphosphate hydrolase. Molecular and Biochemical Parasitology 97, 209-220.

Plesner, L., 1995. Ecto-ATPases: identities and function. International Review of Cytology 158, 141-214.

Schulte am Esch II, J., Sévigny, J., Kaczmarek, E., Siegel, J.B., Imai, M., Koziak, K., Beaudoin, A.R., Robson, S.C., 1999. Structural elements and limited proteolysis of CD39 influence ATP diphosphohydrolase activity. Biochemistry 38, 2248-2258.

Sissons, J., Alsam, S., Jayasekera, S., Khan, N.A., 2004. Ecto-ATPases of clinical and non-clinical isolates of Acanthamoeba. Microbial Pathogenesis 37, 231-239.

Soares, R.M.A., Santos, A.L.S., Bonaldo, M.C., de Andrade, A.F., Alviano, C.S., Angluster, J., Goldenberg, S., 2003. Leishmania (Leishmania) amazonensis: differential expression of proteinases and cell-surface polypeptides in avirulent and virulent promastigotes. Experimental Parasitology 104, 104-112.

Steiger, R.F., Steiger, E., 1977. Cultivation of Leishmania donovani and Leishmania braziliensis in defined media: nutritional requirements. Journal of Protozoology 24, 437-441.

Vasconcelos, E.G., Ferreira, S.T., de Carvalho, T.M.U., De Souza, W., Kettlun, A.M., Mancilla, M., Valenzuela, M.A., Verjovski-Almeida, S., 1996. Partial purification and immunohistochemical localization of ATP diphosphohydrolase from Schistosoma mansoni. Journal of Biological Chemistry 271, 22139-22145.

Xaus, J., Mirabet, M., Lloberas, J., Soler, C., Lluis, C., Franco, R., Celada, A., 1999. IFN- $\gamma$ up-regulates the $A_{2 B}$ adenosine receptor expression in 
macrophages: a mechanism of macrophage deactivation. Journal of Immunology 162, 3607-3614.

Yao, C., Donelson, J.E., Wilson, M.E., 2003. The major surface protease (MSP or GP63) of Leishmania sp. Biosynthesis, regulation of expression, and function. Molecular and Biochemical Parasitology 132, 1-16.
Zimmermann, H., 2001. Ectonucleotidases: some recent developments and a note on nomenclature. Drug Development Research 52, 44-56.

Zlotnick, G.W., Gottlieb, M., 1986. A sensitive staining technique for the detection of phosphohydrolase activities after polyacrylamide gel electrophoresis. Analytical Biochemistry 153, 121-125. 